\title{
A Framework to Improve Urban Revitalization Developed Through a Theoretical Analysis and Critique of Pruitt-Igoe
}

\author{
By Jack Cherniawsky
}

\begin{abstract}
Urban revitalization is a complex task, greatly impacted by which stakeholders have the authority to identify and implement revitalization strategies. This article uses the Pruitt Igoe housing development to critique and explore alternatives to a modernist revitalization approach. Pruitt Igoe was built in 1954 on 57 acres of inner city land characterized by an overrepresentation of impoverishment and consisted of 33 identical 11 -storey towers. Despite improving the quality of housing for residents of the area, Pruitt Igoe quickly deteriorated into an isolating and dangerous environment for residents. Ultimately, revitalization was not achieved and Pruitt lgoe was demolished just 18 years after construction. Analyzing the case of Pruitt lgoe through the theoretical frameworks of advocacy planning, planning as design, and several concepts from Michel Foucault reveals how inequalities and power differences led to some of the project's negative outcomes. Using the considerations derived from these frameworks, the article demonstrates why renewed infrastructure alone is often insufficient to achieve effective urban revitalization. This article advocates that ongoing engagement with residents is critical to identify the complex social circumstances that underpin urban decline and create lasting, effective, and inclusive urban revitalization.
\end{abstract}

\section{Introduction}

Urban revitalization is defined as the "rebirth or revival in conditions or character of a place that has endured a period of decline" (Grodach, Carl, Ehrenfeucht, \& Renia, 2016). Approaches to urban revitalization have been based on different assumptions and theoretical models which have evolved substantially over time (Heskin,1980). Throughout this paper, I will be relating a number of these theories to the case study of Pruitt-Igoe. Through these theoretical lenses, I will expose the rationale and weaknesses of Pruitt-Igoe's attempt at explaining alternative strategies to urban revitalization. After this analysis, I will construct recommendations to be employed for improved urban revitalization moving forward.
Background on Why Revitalization Occurs and its Strategies

Neighbourhoods constantly evolve and develop through movements of people, jobs, services and construction, as well as changes in land-use, zoning and infrastructure (Grodach et al., 2016). Urban decline occurs when these changes happen in a detrimental way. Examples of detrimental change include an exodus of people and services, or an overall reduction in the quality of neighbourhood amenities (Grodach et al., 2016). However, while neighbourhood decline tends to include this exodus, the underlying reasons for decline and the direct impact on the area and its residents varies greatly across neighbourhoods. Urban revitalization consists 
of strategies introduced to reverse the effects of urban decline. There are a number of different ways to pursue urban revitalization depending on the particular theoretical ideologies or interests at play. Within revitalization strategies there are generally two categories of revitalization efforts: place-based revitalization efforts, and revitalization efforts to increase human capital (Grodach et al., 2016). Placebased revitalization efforts focus on improving the built environment of an area facing urban decline through renovation to or construction of new infrastructure (Grodach et al., 2016). The underlying rationale is that a renewed physical environment will attract investors, jobs and new residents to the area, which in turn will provide benefits such as increased job opportunities and more vibrant surroundings (Grodach et.al, 2016). On the other hand, efforts focusing on increasing human capital involve using the skills and capacities of citizens through a much more comprehensive strategy that tries to identify and dismantle the structural social inequality residents face (Grodach et.al, 2016). Revitalization is achieved by providing programs or services to benefit residents based on their unique needs (Grodach et.al, 2016). This could include jobtraining opportunities, food banks, health care or any other service that helps residents overcome the struggles they face. The underlying rationale is that uncovering and addressing the sources of inequality and struggle will improve the residents' lives, which will then improve the overall neighbourhood and attract investors, jobs and new residents into the area (Grodach et.al, 2016). Both types of revitalization efforts possess unique benefits and limitations in practice. Over time both categories of revitalization efforts have been used separately and in combination (Grodach et.al, 2016). However, the majority of revitalization efforts have prioritized place-based efforts (Grodach et.al, 2016).

\section{Pruitt-Igoe - Background}

After World War II, St. Louis, like many other cities across the United States, was experiencing a mass exodus of inner-city residents to the suburbs. This migration was exclusively middle and upper class residents that could afford private automobiles and therefore led to a concentration of poverty in the inner-city (Films on Demand, 2011). Over time, this led to a lack of investment and subsequent decline in the quality of infrastructure in the inner-city (Films on Demand, 2011). Meanwhile, jobs, services and all new, higher quality development followed the migration to the suburbs (Films on Demand, 2011). Due to the concentration of poverty and aging infrastructure, conditions in the inner-city neighbourhoods became deplorable. In many cities, including St. Louis, massive slums emerged in the inner-city (Films on Demand, 2011). Slum landlords ruled these areas and motivated by profit, crammed as many people into these areas as possible, ignoring both safety and hygiene (Films on Demand, 2011). Concurrently, as an increasing number of businesses moved out to the suburbs, the traditional inner-city jobs were lost and unemployment climbed (Grodach et.al, 2016). Eventually this massive deprivation in inner cities was noticed by people outside of these areas (Films on Demand, 2011). The idea of public housing was extremely unpopular at the time (First Run Films, 2011). It was presumed to be communist and "un-American" (Films on Demand, 2011). However, over time, the slums and their residents' struggles became perceived as problematic by the public (Films on Demand, 2011). Concurrently, many powerful groups outside of the slums such as developers, downtown property owners, and municipalities realized the potential benefits of revitalizing the inner-city through replacing the slums. (Films on Demand, 2011). The exact benefits urban revitalization represented for each of these groups will be elaborated on later in the paper; however, it is important to note that these three powerful groups and their realizations were what kickstarted the mass publicity and were the major reason for the widespread push for urban revitalization in inner American cities (Films on Demand, 2011). Due to this effort, a project was created under the federal United States Housing Act of 1949 that delegated funding to municipalities to purchase (in some cases via eminent domain) and clear 
slum areas and then award contracts to private developers update the areas with modern housing (Bristol, 1991). For every unit cleared, a new unit was required to be built (Bristol, 1991). Also, additional funding was offered as incentive to provide public housing or housing for lowincome individuals (Grodach et.al, 2016). These public policies created the movement known as Urban Renewal, which lasted from 1949 until the early 1970's (Grodach et.al, 2016). Pruitt-Igoe was a classic project developed during this movement (Grodach et.al, 2016).

During Urban Renewal, cities were characterized by large-scale redevelopments. According to the National Commission on Urban Problems, 1,054,000 dwelling units were demolished as a result of Urban Renewal, highway, and public housing programs through the year of 1967 (Heskin, 1980). This program was an interesting combination of placebased and human capital-based revitalization efforts. On the surface, it was promoted as a revitalization effort to increase human capital because it was meant to improve the lives of slum residents (Films on Demand, 2011). However, in reality, the efforts turned out to be more of a place-based approach because it "helped residents" by simply building new infrastructure (Heskin, 1980). Overall, this movement of Urban Renewal was controversial because it caused mass displacement of vulnerable families, was promoted by people outside of the inner-city, and resulted in mixed or non-existent benefits to the urban poor who had been the intended beneficiaries of the projects (Grodach et.al, 2016).

\section{Basic Facts}

Pruitt-lgoe was a housing development completed in St. Louis in 1954 (Bristol, 1991). The complex consisted of 33 identical 11 -storey buildings located on 57 acres of slum land that had been acquired through funding provided under the Housing Act of 1949 (Bristol, 1991). The aim of this project was inner-city revitalization. Pruitt-Igoe was to consolidate slum residents into one location so the remaining inner-city slums could be torn down and replaced with housing for a more affluent population (Films on Demand, 2011). Therefore, the population of Pruitt-lgoe was characterized by poverty, as over fifty percent of residents received some form of welfare assistance (Yancey, 1971). PruittIgoe's strategy of revitalization was based on the standard formula of Urban Renewal projects: it was a place-based revitalization effort advertised as a way to increase human capital. The head architect believed Pruitt-Igoe's design would instill ideal values of "clean, safe and democratic" into the residents and raise them out of poverty (Birmingham, 1999). Initially, the project was a success, residents were blown away by the modernity of the complex compared to the slums it replaced (Films on Demand, 2011). According to residents, the complex felt vibrant and people were happy to live there (Films on Demand, 2011). On paper and during its initial period, Pruitt-lgoe sounded like the perfect, permanent solution to the existing social problems and a paradise for a vulnerable population.

\section{Modernism and Urban Revitalization of the Time}

It is important to understand that revitalization efforts during Urban Renewal such as PruittIgoe were developed by professionals who felt these efforts would provide a universal and permanent solution to the urban deprivation that characterized the slums and their populations (Grodach et.al, 2016). During this time, society was generally predominated by the modernist belief that professionals "know better than their clients what ails them in their affairs" (Heskin, 1980). There was minimal critical review of the underlying assumptions and practices of professionals (Rosenau, 1991, p. 5). In the context of revitalization, this translated to revitalization efforts based on widespread policies developed solely by professionals (Young, 2016). This modernist approach to revitalization was shown in Pruitt-Igoe as the plan had no built-in flexibility, safeguards, or community consultation (Heskin, 1980). Instead, the simple generic formula designed for Urban Renewal, was followed: tear down the slums and replace them with modern 
housing (Films on Demand, 2011). There was no unique consideration about why St. Louis' urban decline had occurred and how this nation-wide strategy would work in this particular city (Films on Demand, 2011). This idealistic, simplistic vision of a solution to urban problems and the rigidity they possessed led to massive short-sightedness when the project was implemented. Through the rest of the paper I will critique this modernist perspective and demonstrate how different theories can be applied to reveal the shortcomings of Pruitt-lgoe and to provide recommendations with the aim of improving future approaches to revitalization.

\section{The Story Unfolds}

Pruitt-Igoe did not work out as planned. Vacancy rates began growing almost instantly (Bristol, 1991). The remaining population became increasingly poor and the demographics shifted to include almost exclusively Black American residents (Birmingham, 1991). Elevators that were once believed to be so technologically advanced broke down with increasing frequency and came to be used by residents and staff as public restrooms (Yancey, 1971). The quality of the buildings went downhill and many became abandoned (Bristol, 1991). The area was ravaged by criminal activity (Bristol, 1991). Many of the abandoned buildings became used and controlled by gangs (Films on Demand, 2011). Resident fear increased through all of this while maintenance continued to decrease (Bristol, 1991). Those who could move away did so (Birmingham, 1999). Those that stayed did so solely due to a lack of economic security (Yancey, 1971). The hallways and elevators designed to foster community interaction were now seen by tenants as a set of "gauntlets" to endure and race through to get into the safety of their apartments (Bristol, 1991). The once vibrant, utopian picture of Pruitt-Igoe vanished and was replaced by something that closely resembled the slums it had replaced. However, now the population was much more dissatisfied and lived in a constant state of fear (Films on Demand, 2011). By 1972, just 18 years after the completion of the buildings, the complex was demolished (Birmingham, 1991). How did this horror story happen? How could it have occurred so quickly? What on earth went wrong?

\section{Advocacy Planning and Revitalization}

Revitalization efforts are often started and led by outsiders of the particular area within which they occur (Grodach et.al, 2016). Therefore, these revitalization strategies represent those outsiders' visions and interests and neglect to consider the existing community, its unique context, residents, and problems (Grodach et.al, 2016). Pruitt-Igoe provides an excellent example of this tendency. The revitalization strategy was solely developed by outsiders from the outset and did not achieve a balanced representation of interests. As explained above, during the Urban Renewal period, professionals and their perspectives were dominant (Heskin, 1980). This deference to professionals led to the creation of large-scale standardized master plans designed without flexibility or reflexivity. The professionals and their solutions were touted as be-all, end-all solutions and were implemented without consulting the subject community (Heskin, 1980). Consequently, revitalization was pursued based on a uniform formula across the country regardless of unique community factors: tear down the slums and replace them with modern housing (Films on Demand 2011).

During the 1960's, modernistplanning peaked and this earlier rigid uniform approach of master planning that lacked any kind of community engagement began to be seen as archaic and ineffective at tackling the growing social unrest (Heskin, 1980). People came to believe that planners must be more than technicians following top-down protocol and procedures if they wanted to address the increasingly complicated problems of cities including systemic racial discrimination and unequal wealth distribution (Heskin,1980). Advocacy planning as a theory developed in response to the perceived shortcomings of modernist planning (Heskin, 1980). Advocacy planning emphasizes creating plural plans rather than unitary master plans (Heskin, 1980). Plural plans strive to integrate 
diverse interests as opposed to unitary plans that consider merely efficiency and follow a scientific procedure (Heskin, 1980). The framework to achieve advocacy planning is simple: give different groups in society a professional to represent their interests (Heskin, 1980). The professional then goes into a community, meets its residents, and listens their problems, ideas and interests (Heskin, 1980). This professional acts as an advocate on behalf of the wishes of the community and meets with other professionals who represent different stakeholder groups (Heskin, 1980). Through a collaborative dialogue amongst these different professionals, the best possible solution for that specific context that integrates the most viewpoints possible emerges (Heskin, 1980). Even the biggest proponents of advocacy planning recognize this is an idealistic outcome. Nonetheless, the process is still seen as an extremely necessary part of urban revitalization and urban planning in general as well as a major improvement to the system that existed during the 1950's and 60's (Heskin, 1980). This process adds an important component to the revitalization process- the problems and experiences of residents living in the community in question are actually heard and they have a "seat at the decision-making table," albeit only through a representative (Grodach et.al, 2016). In urban revitalization, advocacy planning is pursued through figuring out from residents what barriers they face in everyday life and what they believe to be the root causes for urban decline in their neighbourhood (Grodach et.al, 2016). Based on this information, revitalization is pursued through creating a tailormade solution to address the residents' unique circumstances and issues (Grodach et.al, 2016).

Advocacy planning was in no way integrated into Pruitt-lgoe, but it can be a useful way to analyze and critique this project. Neither the people of Pruitt-Igoe nor the residents of the slums it replaced were represented by an advocate. Like other Urban Renewal projects, Pruitt-Igoe was created by a generic program that did not consider the context of the slums they proposed to tear down (Birmingham, 1991). There was no community consultation for the project (Birmingham, 1991). No one considered any alternative strategies to tearing down the slums and replacing them with new modern dense housing (Grodach et.al, 2016). The professionals involved in the redevelopment did not determine why the pre-existing slum had formed in St. Louis and what specific problems ailed the neighborhood and its residents. Instead, Pruitt-lgoe was developed based on conventional practices and standardized opinions of professionals about the problems associated with the slums and how to best revitalize any given area (Bristol, 1991). As stated above, the prevailing professional opinion was that improving housing stock would be the catalyst to increase the quality of the neighbourhood and reverse the urban decline that characterized the inner-city slums (Bristol, 1991).

Had an advocacy planning approach been employed, these professionals would have discovered that while the low quality of housing was an issue in St. Louis, this was not the main driver of urban decline, nor was modern housing the most effective way to revitalize the area (Bristol, 1991). In interviews with residents years after Pruitt-Igoe was destroyed, it was found that the biggest problems of living in inner-city St. Louis were the collateral impacts of suburbanizationin particular, the limited access to proximal services and jobs that paid a reasonable wage (Bristol, 1991; Films on Demand, 2011). As stated earlier, suburbanization resulted in a vicious cycle where all reasonably-paying jobs and businesses were incentivized to move to the suburbs where the population was wealthier and therefore had more disposable income to provide revenue for the businesses (Films on Demand, 2011). As the suburbs spiraled up, the inner-city spiraled down. Without a car to get to the suburbs, people were unable to access these jobs and businesses and therefore the population grew increasingly poor and deprived (Films on Demand, 2011). As this concentration of poverty and deprivation reached a more critical level, remaining residents who could go to the suburbs did (Films on Demand, 2011). More businesses and services followed, exacerbating the vicious cycle exponentially (Films on Demand, 2011). 
Had this vital information been gathered from the outset and incorporated in the project, a more effective well-rounded revitalization strategy could have been implemented that improved the housing stock but also attempted to bring more jobs, services, and amenities to the inner-city.

An advocacy approach would also have been preferable for Pruitt-Igoe due to its dynamic nature. Unlike modernist planning, advocacy planning is an ongoing, flexible process (Heskin, 1980). Revitalization does not end when the buildings stand, and the construction workers have gone home. An advocacy approach to address exposed problems could have potentially saved Pruitt-lgoe as the project was going downhill. After Pruitt-Igoe was opened, residents and professionals almost instantly could see the shortcomings and that it was an ineffective solitary catalyst for revitalizing the inner-city of St. Louis (Bristol, 1991). However, the federal policy that created Pruitt-lgoe had no built-in measures to ensure the long-term sustainability of the funded projects (Films on Demand, 2011). Once an Urban Renewal project such as Pruitt-Igoe was built, the government stepped back and no one monitored the results of the revitalization efforts (Films on Demand, 2011). In contrast to this methodology, advocacy planning calls for ongoing community involvement to identify emergent problems and stop them from worsening (Heskin, 1980). In Pruitt-Igoe, this could have been accomplished through asking the residents why the development was failing to launch the revitalization of the inner-city and what challenges or barriers to prosperity the residents continued to face. However, none of this was pursued. The apparent indifference of the professionals and lack of funding for ongoing improvements or modifications to PruittIgoe translated to a quick demise for the project.

The case of Pruitt-Igoe demonstrates that advocacy planning is crucial for sustainable and effective future revitalization strategies. This theory must be integrated into revitalization efforts in two ways. First, there must be a fundamental recognition that the struggles of one community do not necessarily match the struggles in another community and therefore, neither should the revitalization strategies (Grodach et.al, 2016). One size does not fit all for revitalization. Therefore, revitalization efforts must engage in community consultation to obtain accurate firsthand information from current residents on the reasons why urban decline is occurring and what they recommend for solutions. Starting with this information, professionals then tailormake a revitalization strategy in order to ensure its effectiveness (Grodach et.al, 2016). Second, advocacy planning does not end with the creation of the physical infrastructure of a revitalization effort (Grodach et.al, 2016). In the case of Pruitt-Igoe, a retroactive advocacy approach could have potentially addressed the problems of the building complex and created a revamped solution to improve it before a total failure of the project. Neighbourhoods are constantly changing, especially when revitalization is occurring and therefore ongoing community input is crucial to evaluate the effectiveness of the strategies and respond to changing realities (Heskin, 1980). Any revitalization effort should integrate a flexible, continual advocacy approach to nurture and sustain long-term success (Grodach et.al, 2016). Approaching revitalization with the background ideas of advocacy planning will ensure revitalization occurs in an effective, sustainable way that will truly revitalize the urban landscape.

\section{Pruitt-Igoe Through the Lens of Planning as Design}

The demolition of Pruitt-Igoe has been referred to as "the death of modernist architecture" (Bristol, 1991). This label was initially applied because the physical architectural design was cited as the main reason for Pruitt-Igoe's failure (Bristol, 1991). Through more in-depth analysis it is clear design was definitely a major contributor, but not the only reason for the failure. Planning as design is a useful theory that can show the rationale behind Pruitt-Igoe and how the modernist underpinnings of its design contributed to its failure (Bristol, 1991).

The theory of planning as design is founded on the idea that the built form has a significant 
impact on the lives of the individuals exposed to it (Van Assche, Beunen, Duneveld, \& de Jong, 2013). In some cases, this ideology has been used to rationalize "place-based" efforts of urban revitalization based on the belief that renewed infrastructure translates to revitalization. However, planning as design comes in a variety of forms (Van Assche et al., 2013). Most proponents of this theory realize that more than just new infrastructure is required to solve the complicated social problems associated with urban decline. In fact, if design focuses mostly on aesthetics, it is "bound to create problems with use and maintenance and negatively affect daily life" (Van Assche et al., 2013). This means that many factors including, but not limited to accessibility, disruption to social networks, landscaping, interaction with existing infrastructure, maintenance, user experience and community impact must be considered when designing infrastructure for urban revitalization (Carmona, 2002). Pruitt-Igoe neglected these considerations and instead pursued planning as design from a very narrow premise that focused purely on efficiency and aesthetics (Films on Demand, 2011). The idea behind Pruitt-Igoe was that by merely presenting people with nicer places to live, their lives would be improved (Films on Demand, 2011). This narrow approach to planning as design led to massive flaws in its design that contributed to the project's demise (Bristol, 1991).

Pruitt-Igoe's design was flawed from the start due to an excessive emphasis on efficiency that prioritized creating the most residential units possible (Bristol, 1991). Initially, Pruitt-Igoe was designed to include a mix of unit types including high-rise, mid-rise, and walk-ups to attract a diverse population (Bristol, 1991). As well, a number of community centers were proposed to help create a social network in the complex (Bristol, 1991). However, to maximise the number of units and cut costs, the initial complex was transformed (Yancey, 1971). The revised design consisted of 33 identical 11 -storey towers (Yancey, 1971). The only public building left in this new design was one "community center" which was actually an office for property authorities to collect rent and tend to administrative affairs
(Yancey, 1971). This design resulted in a very isolated community because there were no common spaces within which people could interact with their neighbours (Yancey, 1971). According to planning as design theorists, including semi-private space within a community is crucial to fostering a prosperous social network (Seo \& Lee, 2017). These types of spaces lead to an overall improved quality of life for residents (Seo \& Lee, 2017). Therefore, despite improving the quality of housing, residents were not in fact any happier or connected than they had been in the earlier slums (Yancey, 1971). In the later years of Pruitt-Igoe, $78 \%$ of residents were still relatively satisfied with their apartments, but only $49 \%$ were satisfied with living in the project (Yancey, 1971). In the slums, it had been quite the opposite. While there was little satisfaction with the individual units, residents were happy with the neighbourhood (Yancey, 1971). This neighbourhood satisfaction came from the strong social network that had formed over time and was fostered by large amounts of semiprivate space like yards, alleys or open spaces where neighbourly relationships could develop (Yancey, 1917). Pruitt-Igoe destroyed the slums and with them, the social networks. Residents were then thrust into an unfamiliar environment devoid of prior connections that was not designed to foster a new social network (Yancey, 1971). Therefore, it was inevitable the residents of Pruitt-lgoe became isolated and disconnected in their new environment (Films on Demand, 2011).

As stated above, this problem of isolation was exacerbated further because the population was all also struggling to find work and access services. This concentration of poverty and deprivation meant St. Louis had essentially lost one slum and created another (Films on Demand, 2011). However, now residents were not only poor, they were poor and isolated (Yancey, 1971). According to the broken windows subtheory of planning, as a community is more isolated and displeased with the environment, crime increases and people have decreasing motivation to intervene against crimes (Ren \& Zao, 2017). This is exactly what occurred: the population was characterized by mass isolation, 
deprivation and poverty and the residents were overall dismal about life in Pruitt-Igoe (Yancey, 1971 ). In response to this state of affairs, vandalism and violence became rampant (Yancey, 1971). Counterproductive activities including violence, vandalism and specifically graffiti were seen as a form of rebellion against the creators of PruittIgoe (Yancey, 1971). These acts were a vehicle for the residents to express their displeasure with Pruitt-Igoe and to establish ownership of the area (Yancey, 1971). As predicted by the broken windows theory, the effect of this crime was exacerbated because without a community connection and sense of ownership, those who didn't participate in the criminal activity had no incentive to intervene (Yancey, 1971). As well, residents did not interact enough to create meaningful connections and Pruitt-lgoe was too large for individuals to even know who was actually a resident (Yancey, 1971). This meant that many non-residents were able to sneak into the complex and perform illegal acts like prostitution or drug-related activity in the stairwells or on the grounds (Yancey, 1971). As Pruitt-lgoe deteriorated and crime rates grew, the social network that was already extremely weak hit a critical juncture and completely fell apart because people became afraid of their neighbours and merely retreated to the safety of their apartments (Yancey, 1971). The physical environment and its propensity to foster a healthy social network has massive effects on criminality, as shown in the case of Pruitt-lgoe.

The final component of design that really set in motion the demise of Pruitt-Igoe was the lack of quality building materials and maintenance (Yancey, 1971). In order to pursue the highest level of efficiency possible, the whole complex was built with extremely low quality materials (Yancey, 1971). Almost instantly, components of the buildings began malfunctioning (Bristol, 1991). As violence and vandalism came to dominate the complex, the building materials deteriorated even more rapidly (Birmingham, 1991). Furthermore, without ongoing funding from the government after construction, low rents and extremely high vacancy rates left Pruitt-Igoe in a terrible financial position with the inability to make repairs (Films on Demand, 2011). According to broken windows theory, when the physical environment is not maintained, people begin to care less about the environment and abuse it more (Ren \& Zhao, 2017). This happened in Pruitt-Igoe: the elevators broke down more and more frequently, both residents and officials were observed using the elevators as public washrooms, public services such as police or waste removal were provided less and less frequently, (Yancey, 1971). Providers of public services often neglected to come out to calls from Pruitt-Igoe (Birmingham, 1991). At one point, raw sewage was flowing freely through the hallways (Films on Demand, 2011). While these repairs got more expensive and frequent, service and maintenance for the facilities decreased and vacancy rates soared further (Birmingham, 1991). Without the ability to pay for the massive capital repairs needed, more and more buildings were abandoned and soon enough the entire project became uninhabitable and was demolished (Yancey, 1971).

Viewing the design of Pruitt-lgoe through the lens of planning as design reveals that the project was clearly flawed and failed to consider factors beyond aesthetics and efficiency (Bristol, 1991). I have three recommendations for how the failures of Pruitt-Igoe's design and the theory of planning as design should be integrated into future revitalization efforts. First, revitalization efforts must consider and design for fostering a sense of community. As shown by Pruitt-lgoe, revitalization causes significant reconfigurations to the physical environment which impact with whom and how the population interact and inhabit the area. Therefore, revitalization inevitably disrupts existing social networks (Yancey, 1971). For revitalization to function effectively and create an attractive area there must be effort put into designing so as to create a thriving social network (Yancey, 1971). As seen in Pruitt-Igoe, even if the physical infrastructure has been upgraded, without a social network, an area will fail to sustain a positive user experience, fail to attract future development and ultimately fail to revitalize. Second, maintenance must be put at the forefront of the revitalization effort. Maintaining 
the design and quality of infrastructure is crucial for the sustainability of revitalization efforts (Yancey, 1971). Plans and resources dedicated to infrastructure maintenance must be built into revitalization strategies to avoid a downhill spiral of vandalism and deterioration. Third, to tie together the ideas of designing for a social network and maintaining infrastructure, proactive approaches must be integrated into the design of revitalization efforts such as CPTED (Crime Prevention Through Environmental Design). This theory works with the physical infrastructure to make it harder to perform crimes and deteriorate the physical environment through increasing surveillance and target hardening (Seo \& Lee, 2017). It also pursues strategies that increase the social bonds of an area to stop the root causes of crime and increase people's motivation to intervene in crime and maintain the appearance of infrastructure (Seo \& Lee, 2017). Employing a CPTED strategy would have provided enormous benefits to Pruitt-Igoe. It would have increased community bonds and reduced the motivation and opportunity to perform crime. This would have created a more vibrant atmosphere, which would have been more effective at spurring inner-city revitalization. Overall, a planning as design perspective exposes the flaws of PruittIgoe's design and demonstrates that designing for revitalization is a complex process that must consider many factors beyond aesthetics.

\section{Foucault and Pruitt-Igoe}

Michel Foucault was a prominent French philosopher through the mid-20th century who dissected society, forming diverse and influential philosophies about human society, knowledge, power and more (Whistnant, 2012). Foucault did not accept things at face value; he asked, why are things a particular way? Who says it must be so? Why does the storyteller tell that story (Whistnant, 2012)? Foucault's ideas fall under the umbrella of the postmodernist movement which arose as a direct rebellion against the modernist ideology employed in Pruitt-lgoe. While modernists believe that rational objective knowledge may be generated through scientific procedures of investigation without questioning the underlying assumptions, "postmodernism rejects epistemological assumptions, refutes methodological conventions, resists knowledge claims, obscures all versions of truth, and dismisses recommendations" (Rosenau, 1991, p. 1). In the context of revitalization, postmodernism incorporates a critical examination of the policies, practices, and prevailing societal perceptions of revitalization that are taken for granted or perceived as objectively true and beneficial (Rosenau, 1991, p. 1). As a member of the postmodernist movement, Foucault did not accept the knowledge and the prevailing version of truth disseminated in modern society as a given absolute (Whistnant, 2012). Rather, he studied society through analyzing the historical development that led to the particular dominant norms or institutions which underlie accepted policies (Rosenau, 1991, p. 1). From this Foucauldian approach, there is no singular perfect way to pursue revitalization- every attempt involves weakness or flaw in some contexts (Young, 2016). Therefore, when applying a Foucauldian analysis to revitalization one must remember this theoretical base and realize that the point of using this kind of analysis is to critique and question accepted practices, trends and norms.

Foucault studied society in this way to discover the underlying prescriptions, assumptions, and prejudices in communication, which he defined as a discourse (Whistnant, 2012). Discourses are formed by the ideas and experiences a person has been exposed to (Kelly, 2013). Foucault believed all communication pushed a certain agenda that was a product of the speaker's bias (Whistnant, 2012). To Foucault, discourses are vessels to deploy knowledge into the minds of citizens (Whistnant, 2012). Popularly accepted discourses and the knowledge contained within them became deemed as truth (Whistnant, 2012). Truth is not a natural phenomenon; it is a product of the knowledge of a dominant discourse (Whistnant, 2012).

Further, multiple discourses compete contemporaneously until the discourse with the most power dominates and becomes perceived as the truth (Whistnant, 2012). Power, to 
Foucault, is an inescapable force that works in a complex network (Whistnant, 2012). Someone always possesses more power, and relative levels of power are always context-dependent and evolving (Whistnant, 2012). Using Foucault's fluid notion of power and influential discourse, as well as the subjective nature of knowledge and truth, I will examine the case of Pruitt-Igoe and how a Foucauldian analysis might more generally benefit revitalization going forward.

During Urban Renewal (the revitalization movement dominant at the time of Pruitt-Igoe's creation), the discourse that tearing down innercity slums would tackle poverty, inequality and revitalize the inner-city was extremely powerful and therefore this strategy and rationale for revitalization became accepted as truth (Bristol, 1991). As discussed earlier, this discourse was accepted nationally because it was disseminated by powerful groups including developers, downtown property owners, and municipalities. Dissemination by these powerful groups propelled the discourse, enabling it to be prioritized in government policy and funding and to act as a catalyst for the massive movement of Urban Renewal (Films on Demand, 2011). A retrospective review of this discourse and revitalization movement from a Foucauldian perspective reveals the hidden, ulterior motives of the disseminating groups. Downtown property owners pushed for revitalization because revitalizing the inner-city would re-attract people downtown and help fill the growing vacancies (Films on Demand, 2011). Developers wanted revitalization because clearing and redeveloping the slums would offer huge opportunities for construction, jobs and ultimately profit (Films on Demand, 2011). Municipalities realized this inner-city revitalization would eliminate the eyesore of the slums and increase the property taxes they received (Films on Demand, 2011). These groups banded together and through their collective power, were able to mobilize the public to promote urban revitalization. Thus, the dominant discourse came to be that the slums must be torn down. Ultimately, this led to massive financial and legislative support for Urban Renewal through the United States Housing
Act of 1949 (Films on Demand, 2011). This analysis of the hidden benefits of revitalization for all these powerful parties reveals why these groups were so passionate in pushing for innercity revitalization and why such widespread and powerful policy was adopted for revitalization at the time (Films on Demand, 2011). Pruitt-Igoe, like many other revitalization efforts, arose when people outside the community perceived both a problem and an opportunity. They pursued strategies of neighbourhood revitalization that addressed their perceived problem and benefited themselves, rather than focusing on the community's needs (Grodach et.al, 2016). While revitalization efforts often being presented as noble endeavours to help citizens facing urban decline, they are often pushed in order to transform the neighbourhood to pursue profit for developers and municipalities rather than solely to improve the quality and vitality of an urban area (Grodach et.al, 2016). Thus, through a Foucauldian analysis, the underlying discourse and the motives of its proponents of urban revitalization are brought into focus. Going forward, revitalization efforts should be viewed critically in this manner to discover why an area is believed to be in need of revitalization and who stands to benefit the most from a proposed revitalization effort (Grodach et.al, 2016).

Pruitt-Igoe was designed to be desegregated and to attract a diverse population to the center of St. Louis (Films on Demand, 2011). However, this goal was influenced by a number of informal discourses and power relations. Initially, the design was segregated: one third of housing for whites (Pruitt); and, two thirds for housing Blacks (lgoe) (Birmingham, 1999). This design was modified to make the complex desegregated when America became officially desegregated in 1951 (Birmingham, 1999). However, these modifications disregarded competing contradictory formal and informal discourses of the time. Despite official desegregation, the prevalent culture remained very segregated (Birmingham, 1999). Desegregation existing in formal discourses in the form of legislation, but on an informal societal level the discourse of segregation remained much more powerful 
(Birmingham, 1999). Since its inception, America had pursued a strategy of separate development between Black and White Americans, which translated to a visible racially separated landscape and heavily influenced the dominant culture (Birmingham, 1999). After desegregation, Black Americans remained significantly disadvantaged economically and socially (Birmingham, 1999). Furthermore, despite official desegregation policies, vast numbers of White Americans believed that the races should be treated differently and held strong prejudices against Black Americans (Birmingham, 1999). Many White Americans were strongly opposed to taking away racial homogeneity in neighbourhoods and were unwilling to live in the same area as Black Americans (Birmingham, 1999). The inner-city was perceived to be a place reserved for poor Black Americans (Films on Demand 2011). Due to these powerful, competing discourses, no one but impoverished Black Americans would live in Pruitt-lgoe (Birmingham, 1999). This meant that from the beginning, Pruitt-Igoe was completely populated by a single group of severely disadvantaged, impoverished people (Bristol, 1991). This concentration of poverty in a residential area has been proved time and time again to be ineffective in revitalization efforts (Grodach et.al, 2016). These demographics make private investors weary. Therefore, despite improving the built environment, few businesses or jobs are added and the area will still severely struggle (Joseph, Chaskin, Webber, 2007). Pruitt-Igoe was no exception to this. Many believed the project simply "tore down one slum and built another" (Birmingham, 1999).

To combat this problem, revitalization must account for the informal, more insidious discourses about the public perception of areas facing urban decline. An area is only revitalized once it becomes attractive and prosperous (Grodach et.al, 2016). More particularly, revitalization efforts must examine and deconstruct negative discourses about the subject area that inhibit its attractiveness. By removing this negative perception, one can attract a diverse population and provide more appealing demographics for private investors. This in turn benefits all residents by providing more amenities, businesses, services and jobs to deprived areas (Joseph, Chaskin, Webber, 2007). Stigma and prejudice-informal or formal-may exist, as in the case of PruittIgoe, that render revitalization efforts useless. Revitalization must uncover these discourses and determine the means to effectively dismantle them to increase attractiveness of the area undergoing revitalization.

\section{Conclusions: Revitalization Going Forward}

This paper has used three theoretical models to reveal the flaws of urban revitalization in the case of Pruitt-Igoe. While critiquing the case, I raised four ways to improve revitalization going forward. First, I have shown that modernist revitalization is seriously flawed and should be avoided because it leads to overly-simplistic revitalization strategies and fails to adjust to the unique circumstances of urban decline. Second, I have explained that an advocacy approach must be integrated into revitalization and pursued even after the first wave of infrastructure is built. This approach ensures the ongoing effectiveness and sustainability of revitalization efforts. Third, urban decline occurs for much larger reasons than simply the quality and appearance of infrastructure and therefore, revitalization requires more than new infrastructure. While infrastructure is crucial to revitalization, a planning as design perspective that considers wider factors of how the built form can contribute to benefitting the user experience and livability of an area must be integrated into the construction of all infrastructure during revitalization. Fourth, a Foucauldian analysis of the discourses and power relations that affect an area must be examined prior to the initiation of revitalization efforts. This will uncover who is pushing for revitalization, how they will benefit, and how revitalization efforts will be inhibited by the discourses and power relations that exist in society at that time. Overall, a city is a complex system that is constantly changing in good and bad ways. In order to pursue effective, lasting revitalization for an area experiencing negative 
changes, a multilayered analysis must be performed. Revitalized areas have the potential to benefit different groups including private industry, municipalities, and citizens. However, as shown in the case of Pruitt-Igoe, revitalization can go very wrong and create a number of negative externalities. In conclusion, a theoretical analysis and framework including but not limited to the matters addressed in this paper is beneficial to uncover the complex reasons for an area's urban decline and how to effectively revitalize an area.

\section{References}

Birmingham, E. (1999). Reframing the ruins: Pruitt-lgoe, structural racism, and African American rhetoric as a space for cultural critique. Western Journal of Communication, 63, 291-309. https://doi. org/10.1080/10570319909374643

Bristol, K, G. (1991). The Pruitt-Igoe myth. Journal of Architectural Education, 44(3), 161 - 173. https://doi.org/10.1080/10464 883.1991.11102687

Carmona, M., De Magalhaes, C. \& Edwards, M. (2002). Stakeholder views on value and urban design. Journal of Urban Design, 7(2), 145-169. https://doi. org/10.1080/1357480022000012212

Cohen, J.L. (2014). Modernist lessons in postmodernist times. Retrieved from: http:// popupcity.net/jean-louis-cohen-modernistlessons-in-post-modernist-times

Fehler, P. (Producer), Freidrichs, J. (Producer), Woodman, B. (Producer), \& Freidrichs, C. (Director \& Producer). (2011). The PruittIgoe myth [Motion picture]. United States: Unicorn Stencil Documentary Films

Foucault, M. (1988). The History of Sexuality. 1 st Vintage Books ed. New York: Vintage Books.

Grodach, C., \& Ehrenfeucht, R. (2016). Urban revitalization: Remaking cities in a changing world. Basingstoke: Routledge.
Heskin, A.D. (1980). Crisis and response: A historical perspective on advocacy planning. Journal of the American Planning Association. 46(1). 50-63. https://doi. org/10.1080/01944368008977015

Richardson, T. (1996). Foucauldian discourse: power and truth in urban and regional policy making. European Planning Studies, 4(3), 279-292. https://doi. org/10.1080/09654319608720346

Rosenau, P. (1991). Post-Modernism \& the Social Sciences. Princeton: Princeton University Press.

Seo, S., \& Lee, K. (2017). Effects of changes in neighbourhood environment due to the CPTED project on residents' social activities and sense of community: a case study on the Cheonan Safe Village Project in Korea. International Journal of Urban Sciences, 21 (3), 326-343. https://doi.org/10.1080 /12265934.2017.1298462.

Van Assche, K., Beunen, R., Duineveld, M., \& de Jong, H. (2013). Co-evolutions of planning and design: Risks and benefits of design perspectives in planning systems. Planning Theory, 12(2), 177-198. Retrieved from: www.jstor.org/stable/26165957

Whistnant, C. (2012). Foucault and discourse. Retrieved from: http://webs.wofford.edu/ whisnantci/his389/foucault_discourse.pdf Yancey, W. (1971). Architecture, interaction, and social control: The case of a largescale public housing project. Environment and Behavior, 3(1). 3-21. Retrieved from: http://login.ezproxy.library. valberta.ca/login? url=http://search. ebscohost.com/login.aspx? direct= rue $\& \mathrm{db}=$ edselc $\& A N=$ edselc.2-52.0$8496592384 \&$ site $=$ eds-live \&scope $=$ site 